\title{
THE EFFECT OF THE ELECTRICAL CONDUCTIVITY OF SUPERPLASTICIZERS ON THE FLUIDITY AND EARLY HYDRATION PARAMETERS OF CEMENT PASTE
}

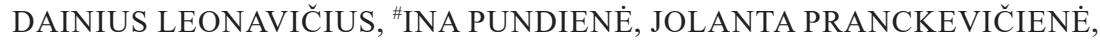 \\ GIEDRIUS GIRSKAS, MODESTAS KLIGYS \\ Institute of Building Materials, Vilnius Gediminas Technical University, Sauletekio av. 11, Vilnius, LT-10223, Lithuania \\ "E-mail: ina.pundiene@vgtu.lt
}

Submitted April 22, 2019; accepted August 5, 2019

\begin{abstract}
Keywords: Admixture, OPC, Spreadability, Viscosity, Temperature
It is important to select a certain type and amount of a superplasticizer (SP) for successful cement applications in concrete. The results show that the SPs ((lignosulphonates (LS), polyacrylates (PA) and polycarboxylates (PCE)) especially differ by their electrical conductivity (EC) values (from 2.5 to 4 times) and mostly influence the spreadability, viscosity, temperature and hydration course of the cement paste with an SP. Compared to the pure cement paste's viscosity, all the tested amounts of LS, PA and PCE lower the initial temperature of the cement paste, but only PCE and PA noticeably reduce the viscosity. It can be highlighted that $L S$, characterised with high EC values causes a rise in the cement paste temperature and a sharp growth in the viscosity. PCE and PA with much lower EC values, reduce the temperature and, correspondingly, the viscosity of the paste. EXO temperature tests revealed that the same amount of SP'S $(0.2 \%)$ has a different effect on the course of the hydration, the EXO maximum time and the temperatures. Compared to the pure cement paste, LS reduced the EXO maximum time by $17 \%$ and lowered the EXO maximum temperature by $6^{\circ} \mathrm{C}$, whereas $P C E$ and PA extended the EXO maximum time by $11.3 \%$ and $12.2 \%$, respectively.
\end{abstract}

\section{INTRODUCTION}

Different superplasticizers (SPs) are used for the purpose of ensuring the good workability of cementitious materials. Lignosulphonates (LS), polycarboxylates (PCE), polyacrylates (PA), and copolymers with a capacity to reduce the involved water content by $5-30 \%$ are used very often among the effective SPs. [1-6]. Traditional SPs like LS, naphthalene and melaminebased polymers are anionic surfactants and disperse the cement particles through a mechanism of electrostatic repulsion.

PCE and PA based superplasticizers disperse the charged cement particles through electrostatic repulsive forces and steric hindrance forces [7-8].

PCE is a group of comb-like polyelectrolytes, usually with poly (acrylic acid-co-acrylic ester/ether) as a backbone and polyethylene oxides (PEO) as the side chains, which makes the polymer anionically charged in an alkaline solution [9]. When the PCE is mixed into the fresh cement paste, the deprotonation of the carboxyl groups in the alkaline condition makes the backbone of the PCE molecules negatively charged and the negative carboxylic groups are adsorbed on the cement particles surface. The side chains prevent the particles from coming closer to each other, and the negatively charged cement particles repel each other. The dispersing effect depends on the number of carboxyl groups; the higher carboxyl groups on the main backbone chain facilitate fast adsorption [10-12].

According to the studies [13-18], steric hindrance plays a major role in the dispersing mechanism. As these negatively charged cement particles repel each other, the water, which is trapped in the agglomerated cement particles, is released, thus, creating the homogeneous dispersion of all the particles. Dispersed in the cement suspension, the PCE particles are involved in the process of cement hydration and create a continuous closepacked layer because the carboxylic groups of the PCE are coupled with $\mathrm{Ca}^{2+}$ ions on the surface of cement particles or on the hydrated products and continue to form complexes $[9,10,17,19]$. All types of PCEs were found to be more adsorbed on the aluminate phase than on the alite phase. During hydration, ettringite is able to adsorb 2 - 4 times more negatively charged PCE than a monosulfate or $\mathrm{C}-\mathrm{S}-\mathrm{H}[12,20]$.

Polymers with a higher molecular weight, lower side chain densities and shorter side chains adsorb stronger on a cement particle than polymers with lower charge densities [21-24]. This finding correlates with the rheological parameters. Researchers have proven that decreasing the density of the side chains enhances the workability (increased mortar spread diameter, viscosity of the cement pastes, lowering of the apparent yield stress and plastic viscosity of the cement pastes) $[17,25]$. It is important to note that PCEs mainly retard the dissolution 
of alite [26]. The amount of adsorbed polymer and the surface coverage of the cement particles by the PCEs can be linked to the retardation effect and the dispersive action of the SP that changes the growth kinetics and morphology of the hydrate phases.

Different SP's exhibit different adsorption behaviours and retardation effects, closely correlating with their specific molecular architecture [24, 27-29]. There may be cases when the composition of the cement and $\mathrm{SP}$ (due to the $\mathrm{pH}$ or concentration of the SP) is not well compatible and it loses mobility very fast or it significantly reduces the hydration rate $[30,31]$. The improvement in the rheological properties depends on the type of the SP. Many studies [32-34] have determined that a PCE-based SP exhibited a substantially larger radius of gyration; therefore, a larger thickness of the polymer layer than other polymers, which required significantly smaller dosages to reach the adsorption. All SPs prolong the induction period and inhibit the hydration reaction related to the higher adsorption rates of the polymers on the aluminate phase than on the alite phase [27, 30, 31, 35-37].

In the study [38, 39], traditional SPs were compared with PCE plasticizers and it was found that (LS), sulfonated naphthalene (PNS), and melamine-type (PMS) SP had higher values of adsorption on the cement grain surface than the PCE. Adsorption was related to the charge density and the configuration of the adsorbed molecules [38]. Traditional SPs like LS, PNS and PMS had 16-20 times higher adsorption values than a PCE for CEM I type cements. Another finding was that the adsorbed quantity of traditional SPs (LS, PMS and PNS) on ettringite was approx. $20 \%$ higher than for a PCE [12]. Adsorption was the most intense in the LS, characterised by the highest number of $\mathrm{R}-\mathrm{SO}^{-3}$ groups originally present in the sulfonates; polymer molecules were directly involved in the adsorption.

The relatively fast workability loss of the cement paste in the presence of LS can be related to the increase in the ionic strength of the suspending medium, which compresses the adsorbed polyelectrolyte layers and weakens the electrostatic repulsion. As a result, van der Waals attraction leads to the re-flocculation of cement particles.

Researchers [37, 40] have pointed out that the workability loss of the cement paste with an LS happens due to the accelerate ettringite formation. In cement pas-tes with traditional SPs, such as LS, the induction period depends on an amorphous ettringite like the semipermeable layer phase formation on the cement grains.

Despite of the numerous SPs with different feature compositions and large quantity of studies, the interaction of different types of SP with Portland cements is still unclear. Therefore, choosing the most suitable type and the optimal amount of the SP as well as the evaluation of the SP behaviour is essential. There are not enough very important detailed studies on how the different SPs influence the cement paste's initial viscosity, temperature and hydration course. In order to extend the knowledge on how to use SPs in cement paste compositions more efficiently, it is absolutely necessary to know how SPs of different types affect the rheological cement properties and influence the cement hydration. Therefore, the research results obtained using the widespread methods are extremely relevant before selecting an SP for the cement.

\section{EXPERIMENTAL}

\section{Materials}

Ordinary Portland cement (OPC) CEM I 42.5 R produced by a local manufacturer in accordance with the requirements of standard EN 197-1 was used for the tests. The OPC had a specific surface of $4200 \mathrm{~cm}^{2} \cdot \mathrm{g}^{-1}$, a bulk density of $1.1 \mathrm{~g} \cdot \mathrm{cm}^{-3}$, an initial setting time of $140 \mathrm{~min}$, a final setting time of $190 \mathrm{~min}$, an alkali content up to $0.8 \%$. The mineral composition in percentages: $\mathrm{C}_{3} \mathrm{~S}-56.64, \mathrm{C}_{2} \mathrm{~S}-16.72, \mathrm{C}_{3} \mathrm{~A}-8.96$, and $\mathrm{C}_{4} \mathrm{AF}-10.59$. The OPC particle size ranged from 1 to $100 \mu \mathrm{m}, 50 \%$ of OPC particles were of $15-30 \mu \mathrm{m}$ size.

The following three types of SP were used in the study: a modified LS-based (A), with a dry matter content of the solution of $31 \%$, with a molecular weight of $35 \mathrm{~g} \cdot \mathrm{mol}^{-1}$; a PA ester based (B), with a dry matter content of the solution of $27 \%$, with a molecular weight of $39.4 \mathrm{~g} \cdot \mathrm{mol}^{-1}$; and a PCE based (C) with a dry matter content of the solution of $27 \%$, with a molecular weight of $51 \mathrm{~g} \cdot \mathrm{mol}^{-1}$. The SPs were used in a liquid state. The distilled water was characterised by a $\mathrm{pH}$ of 5.8 and an electric conduction of $8 \mu \mathrm{S}$, was used.

\section{Preparation of the water solutions, mixture of the formulation and the sample formation}

In order to better describe how the amount of SP will affect the electrical conductivity (EC) and $\mathrm{pH}$ values of the water solution, tests with different amounts of SPs $(0 ; 0.1 ; 0.2 ; 0.3 ; 0.4 ; 0.5 \%)$ in distilled water $(100 \mathrm{~g})$ were made. A special Hobart type mixer was used to help prepare for the investigation the cement pastes. The cement with a water solution containing the SP was mixed for $5 \mathrm{~min}$ by forced mixing at a speed of $56 \mathrm{rpm}$. The temperature of the components and the mixing environment was $20 \pm 1{ }^{\circ} \mathrm{C}$.

In all the cases, the goal of the tests was to find out the effect of the SP on the cement paste spread, viscosity and hydration temperature. The cement paste (compositions presented in Table 1) spread, viscosity and exothermal reaction parameters were measured at the temperature of $20^{\circ} \mathrm{C}$. A W/C ratio of 0.30 was chosen to determine the efficiency of the SP. 
Table 1. The cement paste compositions (in wt. \%).

\begin{tabular}{cccccc}
\hline $\begin{array}{c}\text { Compo- } \\
\text { sition }\end{array}$ & \multicolumn{5}{c}{ Raw materials (\%) } \\
\cline { 2 - 6 } & OPC & SP (A) & SP (B) & SP (C) & W/C ratio* \\
\hline K & 100 & 0 & - & - & 0.3 \\
A-0.1 & 100 & 0.1 & - & - & 0.3 \\
A-0.2 & 100 & 0.2 & - & - & 0.3 \\
A-0.3 & 100 & 0.3 & - & - & 0.3 \\
A-0.4 & 100 & 0.4 & - & - & 0.3 \\
A-0.5 & 100 & 0.5 & - & - & 0.3 \\
B-0.1 & 100 & - & 0.1 & - & 0.3 \\
B-0.2 & 100 & - & 0.2 & - & 0.3 \\
B-0.3 & 100 & - & 0.3 & - & 0.3 \\
B-0.4 & 100 & - & 0.4 & - & 0.3 \\
B-0.5 & 100 & - & 0.5 & - & 0.3 \\
C-0.1 & 100 & - & - & 0.1 & 0.3 \\
C-0.2 & 100 & - & - & 0.2 & 0.3 \\
C-0.3 & 100 & - & - & 0.3 & 0.3 \\
C-0.4 & 100 & - & - & 0.4 & 0.3 \\
C-0.5 & 100 & - & - & 0.5 & 0.3 \\
\hline
\end{tabular}

* over $100 \%$ of dry components

\section{Methods of testing}

The effect of the different amounts of the SP on the values of the $\mathrm{EC}$ and $\mathrm{pH}$ of the water solution were performed with an MPC 227 instrument manufactured by Mettler-Toledo ( $\mathrm{pH}$ sensor InLab 410, measuring accuracy 0.01 ; EC sensor InLab 730, a measuring range of $\left.0-1000 \mathrm{mS} \cdot \mathrm{cm}^{-1}\right)$. Electrical conductivity is a state measured by applying an electrical field between two electrodes $(+$ and -$)$ that initiate an electric current. The Mettler-Toledo device conductivity sensors are based 2 in 1, i.e., both polarities are integrated in one housing, in our case, four ring sensors were used, two rings were used for the voltage engagement and the other two for the current which is proportional to the ionic strength in the solution. For the engagement, an AC (alternating current) voltage is used for the reason of the "plating" affect - ions gathering at the conductivity plates and staying there as immobile particles, thus, decreasing the area of the plates, i.e., the conductivity cell changes. Further signal processing runs with conversion from AC was used for the data output.

For performing the mini-slump test, the paste was filled into a Vicat cone (height of $40 \mathrm{~mm}$, upper diameter of $70 \mathrm{~mm}$, bottom diameter of $80 \mathrm{~mm}$ ), which had been placed on a glass plate. Lifting the cone allowed the paste to spread.

The effect of the different amounts of the SP on the dynamic viscosity of the fresh cement pastes was tested using a vibro-viscometer SV-10 (capacity up to $12.000 \mathrm{mPa} \cdot \mathrm{s}$, accuracy of $0.01 \mathrm{mPa} \cdot \mathrm{s})$. The dynamic viscosity of the fresh cement pastes was measured immediately after the preparation and after 30 minutes. The chosen time corresponds with the actual concrete placing terms.
The hydration characteristics of the fresh cement paste were followed by an exothermic profile in accordance with the ALCOA methodology [41]. The heat generated in the exothermic reactions of the cement minerals in the fresh cement paste was measured at $20^{\circ} \mathrm{C}$ using $1.5 \mathrm{~kg}$ of the specimens placed in an insulated $10 \times 10 \times 10 \mathrm{~cm}$ textolite mould. A thermocouple (type $\mathrm{T}$ ) was embedded in the specimen and linked to the data capture system to record the temperature as a function of time.

\section{RESEARCH RESULTS AND DISCUSSION}

The superplasticizers $\mathrm{pH}$ and electrical conductivity in the water solution

In order to better assess the impact of the amount of SP (A), SP (B) and SP (C) on the water solutions, the $\mathrm{EC}$ and $\mathrm{pH}$ measurements were performed. EC and $\mathrm{pH}$ values of the SP obtained from the manufacturers are presented in Table 2. It is known that the EC depends on the number of the ions in the solution. SP (B) was found to have an alkaline $\mathrm{pH}, \mathrm{SP}(\mathrm{A})$ had a slightly acidic $\mathrm{pH}$, and SP (C) had an acidic $\mathrm{pH}$. We can see that SP (A) had a very high EC, which was 3.9 times higher than the EC of SP (C) and 2.5 times higher than that of the EC of SP (B). Similar EC results of the SP have also been reported in another study [42]. The water solutions of the SP (Figures 1, 2) reveal very similar trends: the highest EC values were recorded in the SP (A) water solution and the lowest values in the SP (C) water solution. While the EC differences between the SP (A), SP (B) and SP $(\mathrm{C})$ solutions supplied by the manufacturers were 2.5 - 3.9 times, the EC differences in their water solutions increased to 2.7 - 5.2 times. SP (A) might have a high EC due to the highest number of $\mathrm{R}-\mathrm{SO}^{-3}$ groups originally present in the sulfonates [39]; the EC in SP (B) and SP (C) depends on the number of carboxyl groups $\mathrm{COO}^{-}$ and the different architecture [12]. Fewer changes were observed in the $\mathrm{pH}$ value of the SP water solutions as they remained relatively stable irrespective of the SP concentration $\%$.

Table 2. The $\mathrm{pH}$ and electric conduction characteristics of the SPs.

\begin{tabular}{ccc}
\hline SP & $\mathrm{pH}$ & $\mathrm{EC}\left(\mathrm{mS} \cdot \mathrm{cm}^{-1}\right)$ \\
\hline $\mathrm{A}$ & 6.89 & 10.10 \\
$\mathrm{~B}$ & 8.10 & 3.86 \\
$\mathrm{C}$ & 4.75 & 2.51 \\
\hline
\end{tabular}




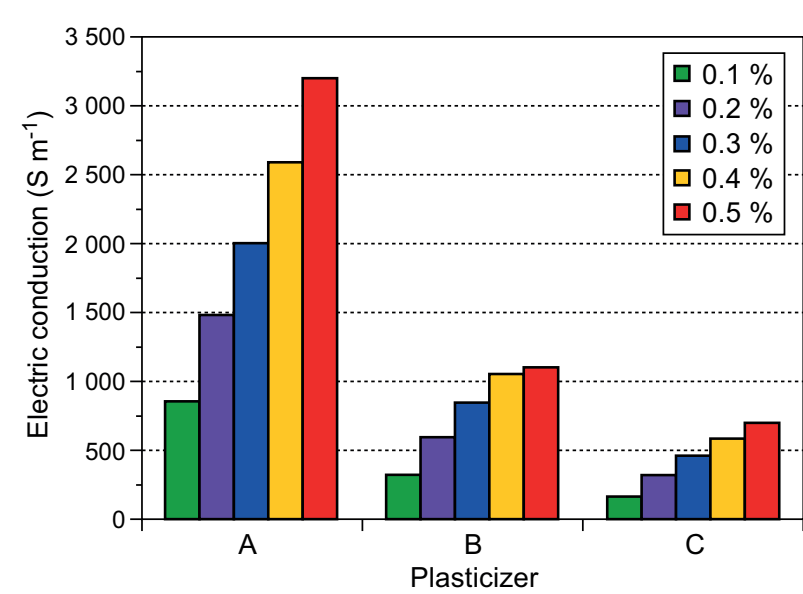

Figure 1. The EC changes of SP (A), SP (B) and SP (C) depending on its amount in the water solution.

Properties of the fresh cement pastes

\section{Density}

The measurements of the fresh cement paste density (Figure 3) revealed noticeable differences when the content of the SP in the mix exceeded $0.2 \%$. The density of the fresh cement paste with SP (B) and SP (C) either increased or remained the same, whereas the density of the fresh cement paste with SP (A) decreased. Similar results have been reported in another study [43], where the observed differences are explained by the different SP type, the effect of the SP characteristics on the bleeding and sedimentation processes in the paste and the entrained air content.

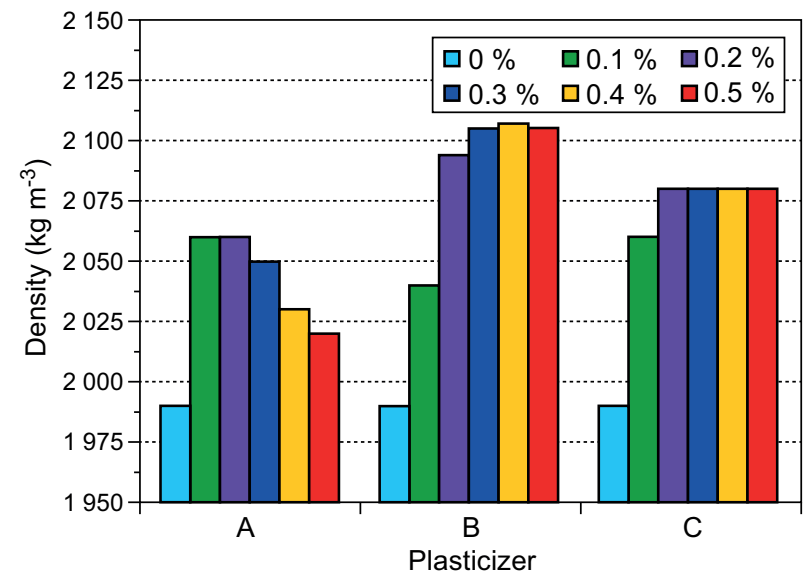

Figure 3. The $\mathrm{pH}$ changes of SP (A), SP (B) and SP (C) depending on its amount in the water solution.

\section{Spread}

An important fluidifying effect of the SP is also manifested by a significant increase in the measured paste spread diameters. The results of the mini-slump tests undertaken immediately after the paste mixing

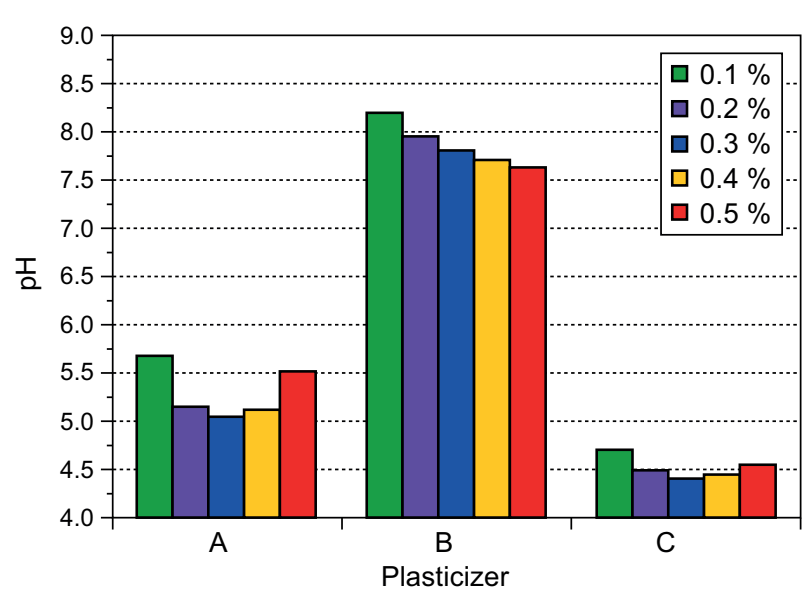

Figure 2. The $\mathrm{pH}$ changes of SP (A), SP (B) and SP (C) depending on its amount in the water solution.

show that at low amounts $(0.1 \%)$ of SP, the best spread is achieved with the pastes containing SP (C) and SP (A) (Figure 4). At the higher amount $(0.2 \%)$ of SP the best spread was observed in the cement pastes containing SP (B) and SP (C). The observed differences in the spread values of the cement pastes containing the SP compared to the reference sample was $52.7 \%, 44 \%$ and $58 \%$ when the SP amount is $0.1 \%$, and $62.7 \%, 80 \%$, and $72.7 \%$ when the SP amount is $0.2 \%$. The conclusion is that at the low amounts of SP in the cement paste, it is difficult to evaluate which SP is the most effective. A further increase in the SP amount in the cement paste showed that the spread of the pastes containing SP (B) and SP (C) did not change or reduced slightly, whereas the spread of the paste containing SP (A) reduced significantly. The low fluidity observed for SP (A) can be explained by the fact that both - the sulfonate groups of SP (A) and the sulphate ion in the cement paste can react with the aluminate phases $\left(\mathrm{C}_{3} \mathrm{~A}+\mathrm{C}_{4} \mathrm{AF}\right)$ to produce ettringite or analogous hydration products $[40,43]$ and,

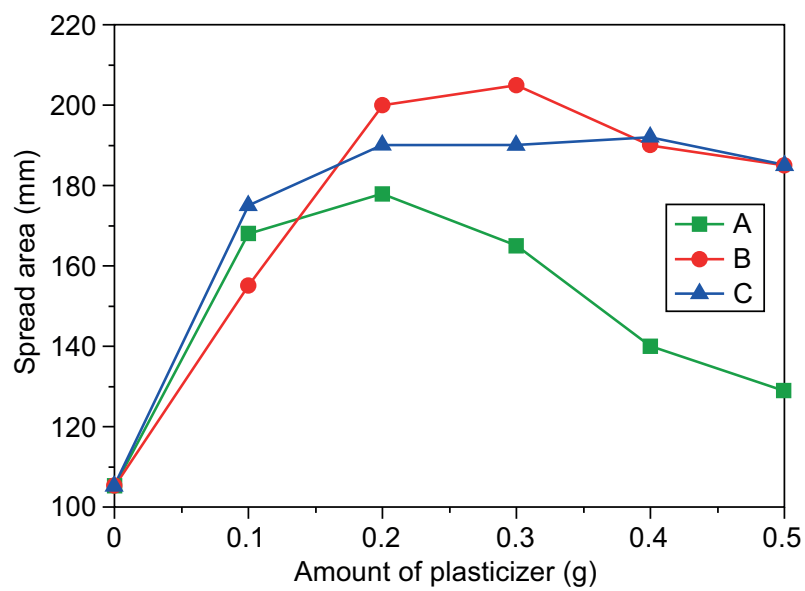

Figure 4. The spread area, in $\mathrm{mm}$, of the cement paste with SP (A), SP (B) and SP (C) depending on the SP amount in the paste. 
as a result, large amounts of ettringite with the shape of large needles are produced. In this case, the hydration of the interstitial phase continues to produce large amounts of ettringite, which causes the stiffness and the pseudosetting of the paste. As we may see, the results of the fresh density tests correlate with the spread tests results. Figure 5 illustrates the increase or decrease (in \%) of the spread area of the cement paste containing three different SPs depending on the SP amount in the paste. The spread curves show that at higher SP amount in the paste $(0.3-0.5 \%)$, SP (C) influences the spread of the paste the least, and SP (A) significantly reduces the spread.

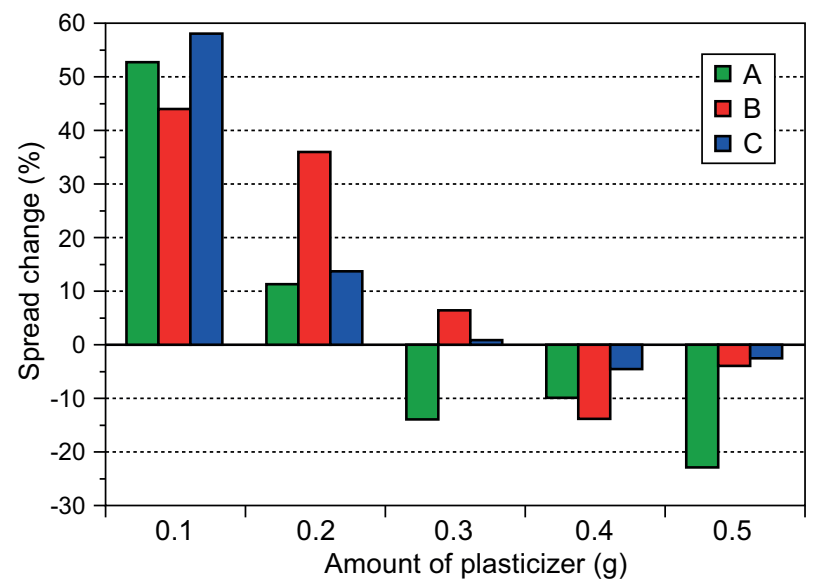

Figure 5. The spread change (in \%) in the cement pastes compared to the spread values at the lower SP content in the paste.

\section{Dynamic viscosity and temperature}

Tests of the viscosity change over time in the cement pastes with the same amount of SP (compositions are presented in Table 1) were conducted to evaluate the workability of the pastes. Compared to the viscosity of the pure cement pastes $(\mathrm{K})$ without any SP, the viscosity of the samples with SP (A) (Figure 6a), characterised by high EC values, reduced the viscosity just for a short period time (about 2 - $3 \mathrm{~min}$ ). From the results of Figure 1 , we can see that at the SP (A) amount of $0.1 \%$ and $0.2 \%$, the EC of the solution changed in the range of $680-1245 \mu \mathrm{S}$.

An increase in the SP (A) amount in the paste from $0.3 \%$ to $0.5 \%$ (the EC of the solution increased more than $1500 \mu \mathrm{S}$ ) immediately increased the viscosity, which reached the maximum viscosity value after $5-10 \mathrm{~min}$. The test results proved that a higher amount of SP (A) is ineffective and can even have a negative effect of the workability of the paste. The authors [44] state that in the presence of sulfate ions, a decrease in the cement paste fluidity is observed. According to the test results reported in the study, the fluidity may reduce 3 times with the increase of sulfate ion concentration in the paste. The lignosulphonates accelerate the formation of ettringite and, therefore, the quick setting of the paste is observed $[37,40]$. Lignosulphonates are known to react with $\mathrm{C}_{3} \mathrm{~A}$; therefore, an accelerated ettringite formation after about 7 minutes of hydration almost exclusively shows the presence of ettringite. Other scientists [37], however, specify that in the presence of lignosulphonates, $\mathrm{C}_{3} \mathrm{~A}$ reacts directly with the gypsum (contained in cement) to form ettringite and the reaction rate is significantly increased. The ability of lignosulphonates to form a complex calcium may explain the accelerated ettringite formation in the $\mathrm{C}_{3} \mathrm{~A} /$ gypsum pastes. The test results referred above explain the sharp increase in the viscosity value in the paste with a higher amount of SP (A).

These findings are also explained by the temperature changesduring theviscositymeasurementtests(Figure 6b). The higher the content of SP (A) is in the paste, the lower the paste's temperature immediately after mixing is. After 5 minutes, a significant temperature increase of $4-6{ }^{\circ} \mathrm{C}$ is observed in the pastes with a higher content of SP (A). This temperature rise has a direct effect on the paste's viscosity, which increases abruptly. The temperature changes in the samples

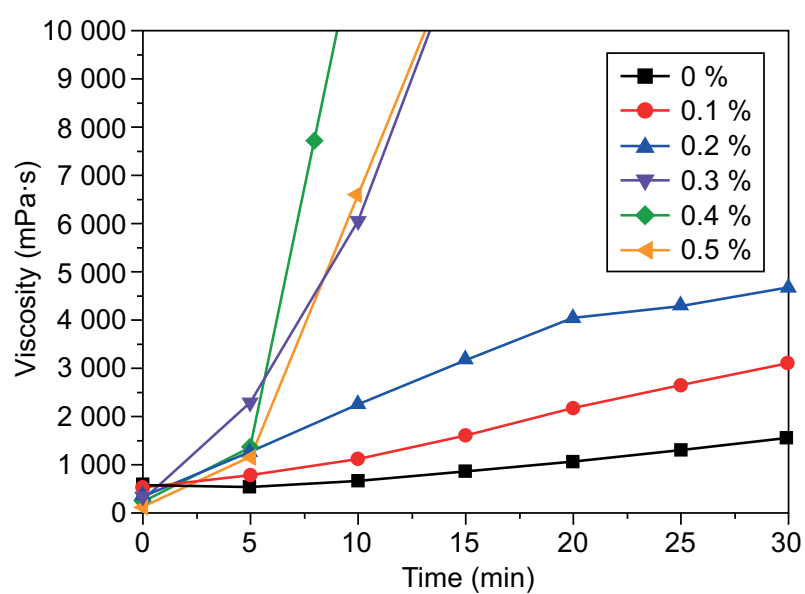

a)

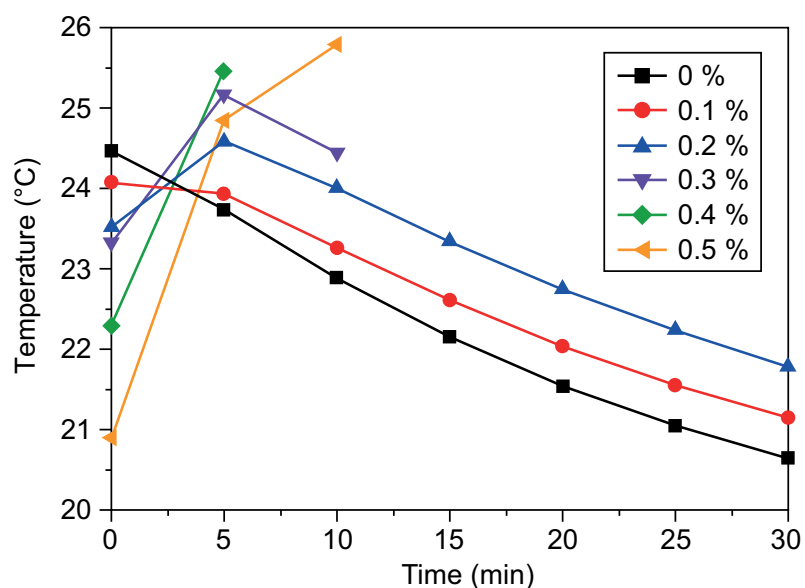

b)

Figure 6. The viscosity and temperature changes of the cement paste with SP (A) depending on time. 
showed that cement pastes with a sharp increase in viscosity also experience a fast temperature increase. As reported in [40], lignosulphonate causes a rapid rise in temperature immediately after mixing, which, in the author's opinion, is associated with the rapid reaction of the aluminate phases of the cement; it accelerates the ettringite formation, but is more effective at retarding C3S hydration.

Compared to the viscosity of the pure cement paste, all the amounts of SP (C) noticeably reduced the viscosity of the cement paste (Figure 7a). In this case, the viscosity is at least two times lower compared to the viscosity of the pastes containing SP (A). We can see that the amount of $0.2 \%$ is sufficient because higher amounts of SP (C) do not cause a significant viscosity reduction. The temperature changes in the pastes (Figure $7 \mathrm{~b}$ ) revealed that all the samples containing SP (C) had a lower temperature after mixing compared to the reference sample. However, the temperatures of the samples containing $0.1-0.4 \%$ of SP (C) were very similar and the lowest temperature was observed in the sample containing $0.5 \%$ of SP (C) after mixing. Only this sample

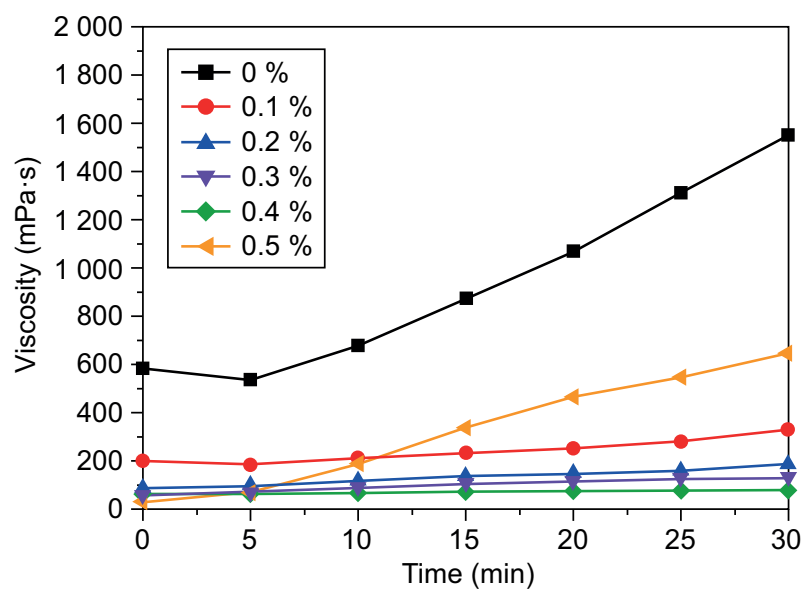

a) demonstrated a temperature rise within the first $5 \mathrm{mi}$ nutes. This temperature rise is reflected in the sample's viscosity curve, which illustrates a sharp increase in the viscosity. The authors state [26] that a PCE based SP, which has a 2 - 3 times higher molecular weight and a longer side chain compared to an acrylic SP, may ensure the low viscosity values for a long time. A higher SP amount and, respectively, a larger quantity of ions (the EC of the SP (C) solution reaches $800 \mu \mathrm{S}$ ) induces a more active reaction with $\mathrm{C}_{3} \mathrm{~A}$, which is followed by the ettringite formation and a corresponding growth in the viscosity.

Very similar changes in the viscosity were observed in the cement paste containing SP (B) (Figure 8a). However, the temperature changes in this paste (Figure $8 \mathrm{~b}$ ) differ from the changes observed in the paste containing SP (C). Lower amounts of SP (B) $(0.1-0.2 \%)$ reduce the initial temperature of the paste, whereas higher amounts $(0.3-0.5 \%)$ increase the temperature. The higher the amount of SP (B) is in the paste, e.g., $0.5 \%$, the higher the temperature rise is. This relationship is seen in the viscosity curve. The authors state [26] that a polyacrylate

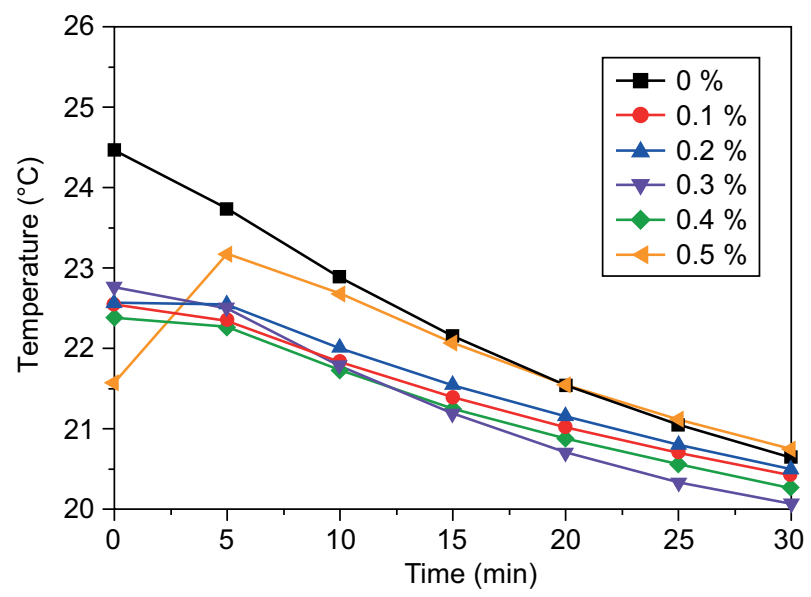

b)

Figure 7. The viscosity and temperature changes of the cement paste with SP (C) depending on time.

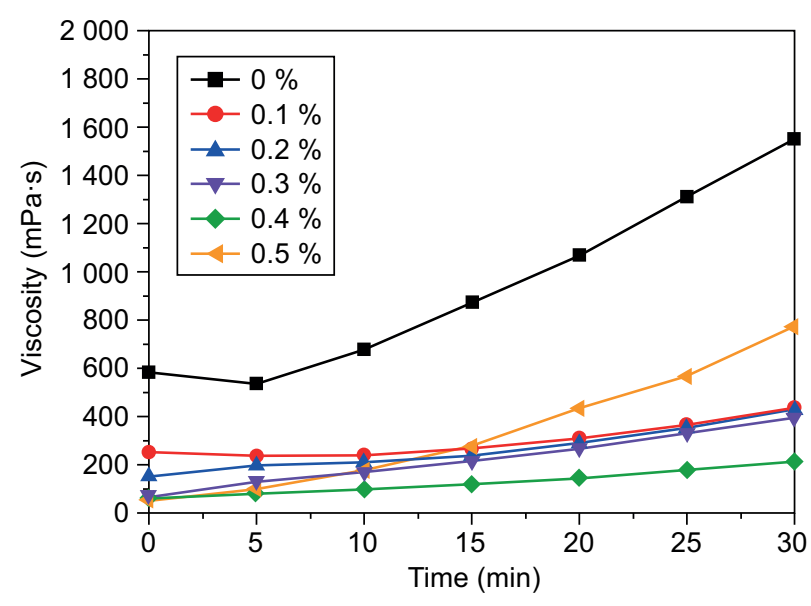

a)

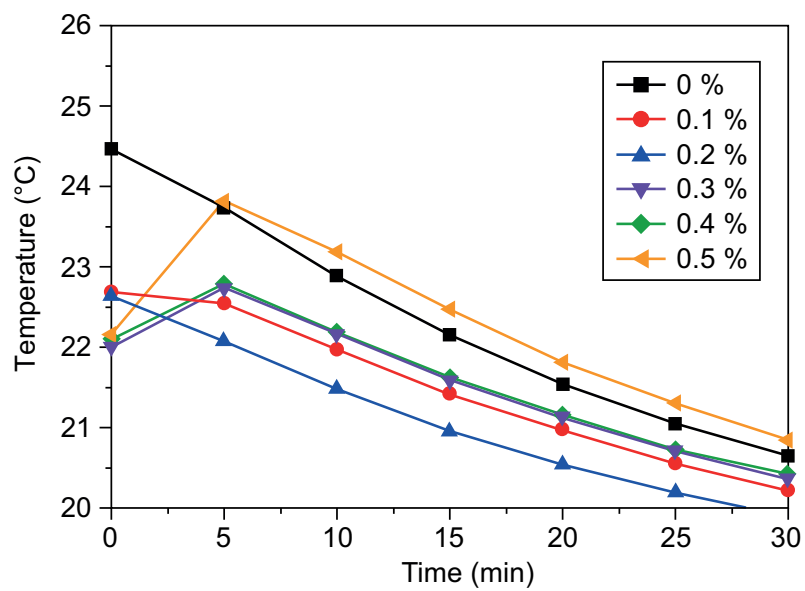

b)

Figure 8 . The viscosity and temperature changes of the cement paste with SP (B) depending on time. 
ester based PCE with a shorter backbone and a longer side chain, as well as higher chain density, which is responsible for the quantity of ions in the solution, has a slightly shorter plasticizing effect in the cement pastes. According to the study [9], the higher concentrations of the ionic functional groups in the aqueous phase delay the setting of cement paste. Due to higher EC values in the SP (B) solution, and the corresponding quantity of ions (the EC of the solutions reached $1200 \mu \mathrm{S}$ at the SP (B) amount of $0.5 \%$ ), the cement paste temperature was higher than in the cement paste with the same amount of $\mathrm{SP}$ (C).

A detailed analysis of the temperature changes is presented in Figure 9, illustrating the comparative temperature changes in the cement pastes after the first 5 minutes, compared to the reference sample. It is clearly seen that SP (A) acts very differently than SP (C) and SP (B). The increase in the SP (A) amount continuously raises the paste's temperature up to $2.5^{\circ} \mathrm{C}$, as well as the viscosity, compared to the reference sample. SP (C) and SP (B) act differently, i.e., they reduce the temperature and viscosity of the paste. The temperature drops by $1.5^{\circ} \mathrm{C}$ when compared to the reference sample.

It can be concluded, that the mini-slump cone and fresh density tests conducted immediately after mixing the cement with water are not sufficient to evaluate the effectiveness of the SP. The analysis of the viscosity and temperature changes over time can significantly supplement the knowledge and explain the SP's effect on the rheological properties of the paste.

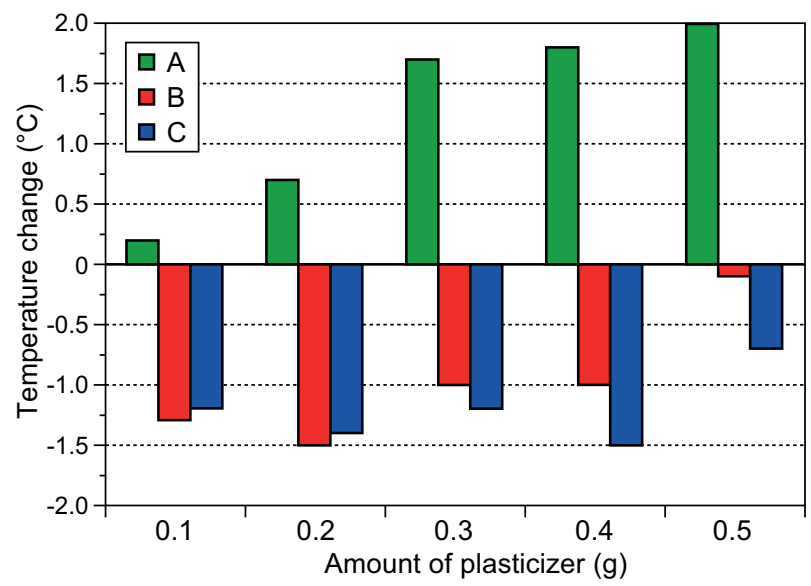

Figure 9. The effect of the SP type and amount on the cement paste's temperature.

\section{Maximum temperature and the time of the exothermic reaction}

As it was experimentally found that the optimal amount of all the used SP's ranges between $0.1-0.3 \%$, the cement pastes containing $0.2 \%$ of SP's were selected for the tests of the EXO process. The studies of the cement hydration process reflected in the exothermal reaction
(EXO) temperature and time (Figure 10) show that SP (A), irrespective of its mildly acidic $\mathrm{pH}$, accelerates the hydration process by $\sim 90$ minutes compared to the reference sample. This finding confirms the previous assumptions that sulfonate groups of this SP actively react with $\mathrm{C}_{3} \mathrm{~A}$ and, thus, increase the initial temperature of the paste, because the rising temperature of the paste can activate the ions in the solution and promote the formation of ettringite in the hardened paste. However, it is difficult to accurately assess that, because no measurements were made in the hardened cement paste. The EXO maximum in the paste with SP (A) was reached after 450 minutes. However, the EXO maximum temperature in the sample with SP (A) reaches $84{ }^{\circ} \mathrm{C}$ only and it is $6{ }^{\circ} \mathrm{C}$ lower than that of the reference sample. In the sample with SP (C), the EXO effect maximum was reached after 596 minutes with the maximum temperature of $88.9^{\circ} \mathrm{C}$. In the sample with SP (B), the EXO effect maximum was reached after 635 minutes with the maximum temperature of $90.5^{\circ} \mathrm{C}$. Both SP (C) and SP (B) extend the hydration time by $1-1.5 \mathrm{~h}$, however they have almost no effect on the EXO maximum temperature.

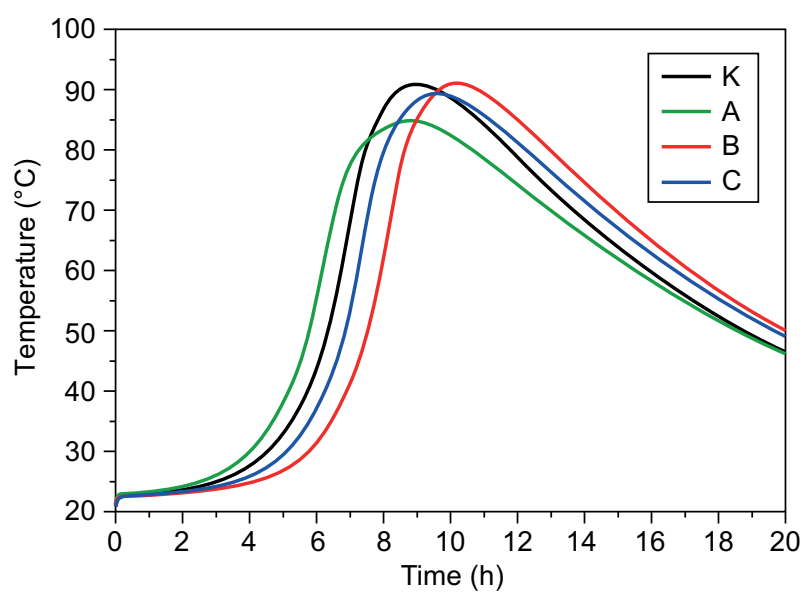

Figure 10. The EXO changes over time in the reference cement paste and in the cement pastes containing $0.2 \%$ of SP (A), SP (B) and SP (C).

\section{CONCLUSIONS}

It has been established that the PCE based SP (C), the PA based SP (B) and the LS based SP (A) differ by molecular weight and especially by the EC values (from 2.5 to 4 times). SPs have water solution $\mathrm{pH}$ values ranging from acidic (for SP (C) and SP (A), to alkaline (for SP (B)). The spreadability, viscosity and temperature and hydration course of the cement paste with SPs mostly depends on the EC values in the water solution.

The cement paste with SP (A), characterised by the highest EC values, demonstrates good spreadability and low viscosity only at the lower SP (A) amounts (0.1 - $0.2 \%)$, when SP (A) solution's EC does not exceed 
$1500 \mu \mathrm{S}$. At the higher amounts $(0.3-0.5 \%$, when the EC increased to $3230 \mu \mathrm{S}$ ), in contrast to the SP (B) and SP (C) results, the spreadability and viscosity of the paste deteriorates significantly. The spreadability of the cement pastes with SP (B) and SP (C) does not deteriorate much at higher amounts of the SP, and the viscosity remains low, because the EC values of the SP does not exceed $1500 \mu \mathrm{S}$. Compared to pure cement paste's viscosity, all the amounts of SP (A), SP (B) and SP (C) lower the initial temperature of the cement paste, but only SP (C) and SP (B) noticeably reduce the viscosity. The viscosity and, correspondingly, the temperature increase are in proportion to the SP (A) amount in the cement paste. It can be highlighted that SP (A), characterised with a high $\mathrm{EC}$ causes a rise in the cement paste temperature and a sharp growth of viscosity, SP (C) and SP (B) with a much lower EC, reduce the temperature and, correspondingly, the viscosity of the paste.

The optimal amount of SP (A), which ensures a lower viscosity in the short run, is $0.1 \%$. For SP (B) and SP (C), this amount should not exceed $0.2 \%$ to prevent the retarding of the hydration.

A mini-slump test alone is insufficient to evaluate the rheological properties of an SP. A simultaneous measuring of the EC, the viscosity and temperature of the SP can provide useful information, which help to evaluate the SP's behaviour in the short and long run.

The EXO temperature tests revealed that the same amount of plasticizer $(0.2 \%)$ has a different effect on the course of the hydration, the EXO maximum time and temperatures. Compared to the pure cement paste sample, plasticizer A reduced the EXO maximum time by $17 \%$ and lowered the EXO maximum temperature by $6{ }^{\circ} \mathrm{C}$. Plasticizers $\mathrm{C}$ and $\mathrm{B}$ extended the EXO maximum time by $11.3 \%$ and $12.2 \%$, respectively, compared to the pure cement paste sample. The EXO maximum temperature for both plasticizers had very little difference from that of the reference sample.

\section{REFERENCES}

1. Nawy E.G. (2001). Fundamentals of High-Performance Concrete. $2^{\text {nd }}$ ed. John Wiley and Sons.

2. Ушеров-Маршак О. (2005). Химические и минеральные добавки в бетон. Колорит.

3. Mangane M.B.C., Argane R., Trauchessec R., Lecomte A., Benzaazoua M. (2018): Influence of superplasticizers on mechanical properties and workability of cemented paste backfill. Minerals Engineering, 116, 3-14. doi: 10.1016/j. mineng.2017.11.006

4. Simon D., Grabinsky M.W., Bawden W. (2011). Effect of polycarboxylated acrylic acid polymer-based superplasticizer on cemented paste backfill. in: Proceedings of the Canadian Geotechnical Conference. Toronto pp. 2-6,

5. Houst Y. F. (1999). New superplasticizers: From research to application. in: Proceedings of International Conference on Modern concrete materials: binders, additions and admix- tures. London, pp. 445-456.

6. Kashcheev D., Zemlyanoi K.G., Kormina I.V., Markova S.V. (2011): Effect Of Surfactants On Aluminosilcate Refractory Properties. Refractories and Industrial Ceramics, 52(2), 298-303. doi: 10.1007/s11148-011-9382-1

7. Huynh L., Beattie D.A., Fornasiero D., Ralston J. (2006): Effect of polyphosphate and naphthalene sulfonate formaldehyde condensate on the rheological properties of dewatered tailings and cemented paste backfill. Minerals Engineering, 19(1), 28-36. doi: 10.1016/j.mineng.2005.05.001

8. Ouattara D., Yahia A., Mbonimpa M., Belem T. (2017): Effects of superplasticizer on rheological properties of cemented paste backfills. International Journal of Mineral Processing, 161, 28-40. doi:10.1016/j.minpro.2017.02.003

9. Tian H., Kong X., Su T., Wang D. (2019): Comparative study of two PCE superplasticizers with varied charge density in Portland cement and sulfoaluminate cement systems. Cement and Concrete Research, 115, 43-58. doi: 10.1016/j. cemconres.2018.10.003

10. Chen B. (2013): Synthesis and properties of an AMPS-modified polyacrylic acid superplasticizer. Journal of Wuhan University of Technology - Materials Science Edition, 28, 566-573. doi: 10.1007/s11595-013-0732-3

11. Aiad I., El-Sabbagh A.M., Adawy A. I., Shafek S.H., AboEL-Enein S.A. (2018): Effect of some prepared superplasticizers on the rheological properties of oil well cement slurries. Egyptian Journal of Petroleum, 27(4), 1061-1066. doi: 10.1016/j.ejpe.2018.03.011

12. Plank J., Hirsch C. (2007): Impact of zeta potential of early cement hydration phases on superplasticizer adsorption. Cement and Concrete Research, 37(4), 537-542. doi: 10. 1016/j.cemconres.2007.01.007_

13. Felekoglu B., Sarkahya H. (2008): Effect of chemical structure of polycarboxylate-based superplasticizers on workability retention of self-compacting concrete. Construction and Building Materials, 22(9), 1972-1980. doi: 10.1016/j.conbuildmat.2007.07.005

14. Winnefeld F., Becker S., Pakusch J., Götz T. (2007): Effects of the molecular architecture of comb-shaped superplasticizers on their performance in cementitious systems. Cement and Concrete Composites, 29(4), 251-262. doi: 10. 1016/j.cemconcomp.2006.12.006

15. Kim G.M., Nam I.W., Yoon H.N., Lee H.K. (2018): Effect of superplasticizer type and siliceous materials on the dispersion of carbon nanotube in cementitious composites. Composite Structures, 185, 264-272. doi: 10.1016/j. compstruct. 2017.11.011

16. Wang X., Zhang J., Yang Y., Shu X., Ran Q. (2018): Effect of side chains in block polycarboxylate superplasticizers on early-age properties of cement paste. Journal of Thermal Analysis and Calorimetry, 133(3), 1439-1446. doi: 10. 1007/s10973-018-7231-X_

17. Cao Q., Lv S.H., Li D. (2012): Study on dispersion properties of an amphoteric polycarboxylate superplasticizer on cement pastes. Advanced Materials Research, 502, 208-211. doi:10.4028/www.scientific.net/amr.502.208

18. Vasilik P.G. (2003): New dispersants (deflocculants) for the production of refractory castables," Novye Ogneupory, 8 , 28-31.

19. Zhang Y., Cai X., Kong X., Gao L. (2017): Effects of combshaped superplasticizers with different charge characteristics on the microstructure and properties of fresh cement pastes. Construction and Building Materials, 155, 441-450. 
doi: 10.1016/j.conbuildmat.2017.08.087

20. Meier M.R., Napharatsamee T., Plank J. (2017): Dispersing performance of superplasticizers admixed to aged cement Construction and Building Materials, 139, 232-240. doi: 10.1016/j.conbuildmat.2016.12.126_

21. Pundienė I., Stonys R., Goberis S., Antonovič V. (2007): Properties of suspension and pastes of different types of microsilica with various deflocculants. Materials Science, 13, 317-321.

22. Ouattara D., Yahia A., Mbonimpa M., Belem T. (2013) Rheology of cemented paste backfill incorporating superplasticizers. in: Proceedings of the $66^{\text {th }}$ Canadian Geotechnical Conference and the $11^{\text {th }}$ Joint CGS/IAH-CNC Groundwater Conference. Montreal.

23. Kong X.M., Li Q.H. (2009): Properties and microstructure of polymer modified mortar based on different acrylate latexes. Journal of the Chinese Ceramic Society, 37, 107-114.

24. Zhang Y.R., Kong X.M., Lu Z.B., Lu Z.C., Hou S.S. (2015): Effects of the charge characteristics of polycarboxylate superplasticizers on the adsorption and the retardation in cement pastes. Cement and Concrete Research, 67, 184196. doi: 10.1016/j.cemconres.2014.10.004

25. Guo Y., Ma B., Zhi Z., Tanc H., Liu M., Jian S., Guo Y. (2017): Effect of polyacrylic acid emulsion on fluidity of cement paste. Colloids and Surfaces, 535, 139-148. doi: 10.1016/j.colsurfa.2017.09.039

26. Plank J., Schroefl C., Gruber M., Lesti M., Sieber R. (2009): Effectiveness of Polycarboxylate Superplasticizers in Ultra-High Strength Concrete: The Importance of PCE Compatibility with Silica Fume. Journal of Advanced Concrete Technology, 7(1), 5-12. doi: 10.3151/jact.7.5

27. Kong F., Pan L., Wang C., Zhang D., Xu N. (2016): Effects of polycarboxylate superplasticizers with different molecular structure on the hydration behavior of cement paste. Construction and Building Materials, 105, 545-553. doi: 10.1016/j.conbuildmat.2015.12.178

28. Feng H., Pan L., Zheng Q., Li J., Xu N., Pang S. (2018): Effects of molecular structure of polycarboxylate superplasticizers on their dispersion and adsorption behavior in cement paste with two kinds of stone powder. Construction and Building Materials, 170, 182-192. doi: 10.1016/j. conbuildmat.2018.02.195

29. Li X., Zheng D., Zheng T., Lin X., Loua H., Qiu X. (2017): Enhancement clay tolerance of PCE by ligninbased polyoxyethylene ether in montmorillonite-contained paste, Journal of Industrial and Engineering Chemistry, 49, 168-175. doi: 10.1016/j.jiec.2017.01.024_

30. Pourchet S., Comparet C., Nicoleau L., Nonat A. (2007) Influence of polycarboxylate superplasticizers on tricalcium silicate hydration. in: Proceedings of the $12^{\text {th }}$ International Congress on the Chemistry of Cement- ICCC, Montréal, pp. 132-145.

31. Zingg A., Winnefeld F., Holzer L., Pakusch J., Becker S., Figi R., Gauckler L. (2009): Interaction of polycarboxylate-based superplasticizers with cements containing different $\mathrm{C}_{3} \mathrm{~A}$ amounts. Cement and Concrete Composites, 31, 153-162. doi: 10.1016/j.cemconcomp.2009.01.005_
32. Spiratos N., Page M., Mailvaganam N.P., Malhotra V.M., Jolicieur C. (2006). Superplasticizers for concrete. Fundamentals, technology and practice, $2^{\text {nd }}$ ed. Quebec, Canada.

33. Mollah M.Y.A., Adams W.J., Schennach R., Cocke D.L. (2000): A review of cement - superplasticizer and their model. Advances in Cement Research, 12(4), 153-161. doi: 10.1680/adcr.2000.12.4.153

34. Alonso M.M., Palacios M., Puertas F., de la Torre A.G., Aranda M.A.G. (2007): Influencia de la estructura de aditivos basados en policarboxilato sobre el comportamenito reológico de pastas de cemento. Materiales de Construccion, 57(286), 65-81. doi:10.3989/mc.2007.v57.i286.48_

35. Ouattara D., Mbonimpa M., Yahia A., Belem T. (2018): Assessment of rheological parameters of high density cemented paste backfill mixtures incorporating superplasticizers. Construction and Building Materials, 190, 294-307. doi:10.1016/j.conbuildmat.2018.09.066

36. Darweesh H.H.M. (2014): Utilization of Ca-Lignosulphonate Prepared From Black Liquor Waste as a Cement Superplasticizer. Journal of Chemistry and Materials Research, $1(2), 28-34$.

37. Collepardi M., Monosi S., Moriconi G., Pauri M. (1985): Influence of Gluconate, Lignosulfonate, and Glucose Admixtures on the Hydration of Tetracalcium Aluminoferrite in the Presence of Gypsum with or without Calcium Hydroxide. Journal of the American Ceramic Society, 68(5), 126-128. doi: 10.1111/j.1151-2916.1985.tb15330.x

38. Flatt R.J., Houst Y.F. (2001): A simplified view on chemical effects perturbing the action of superplasticizers. Cement and Concrete Research, 31(8),1169-1176. doi: 10.1016/ s0008-8846(01)00534-8

39. Burgos-Montes O., Palacios M., Rivilla P., Puertas F. (2012): Compatibility between superplasticizer admixtures and cements with mineral additions. Construction and Building Materials, 31, 300-309. doi: 10.1016/j.conbuildmat. 2011. 12.092

40. Bishop M., Barron A.R. (2006): Cement Hydration Inhibition with Sucrose, Tartaric Acid, and Lignosulfonate: Analytical and Spectroscopic Study. Industrial \& Engineering Chemistry Research, 45(21), 7042-7049. doi: 10. 1021/ie060806t

41. Alcoa calcium aluminate cement test methods brochure, revision 5, available through Alcoa Industrial Chemicals, Frankfurt, 1999 (08/99).

42. Pundienė I., Kičaitė A., Pranckevičienè J. (2016): Impact of different types of plasticizing admixtures on the rheological properties and hydration of blended cements. Journal of thermal analysis and calorimetry, 123(2), 1099-1109. doi: 10.1007/s10973-015-5020-3

43. Mikanovic N., Jolicoeur C. (2008): Influence of superplasticizers on the rheology and stability of limestone and cement pastes. Cement and Concrete Research, 38(7), 907-919. doi: 10.1016/j.cemconres.2008.01.015

44. Sakai E., Yamada K., Ohta A. (2003): Molecular structure and dispersion-adsorption mechanisms of comb-type superplasticizers used in Japan. Journal of Advanced Concrete Technology, 1(1), 16-25. doi:10.3151/jact.1.16_ 